\title{
The Moderating Role of Advance Manufacturing Technology (AMT) On the Relationship between LARG-Supply Chain and Supply Chain Performance
}

\author{
Raghed ibrahim Esmaeel ${ }^{1,2}$, Inda Sukati ${ }^{3} \&$ Noriza Mohd Jamal $^{4}$ \\ ${ }^{1}$ University of Mosul, Faculty of Administration and Economics, Department of industrial management, Mosul, \\ Iraq \\ ${ }^{2}$ Postgraduate candidate, Department of Business Administration, Faculty of Management, Universiti Teknologi \\ Malaysia, Skudai, Johor Bahru, Malaysia \\ ${ }^{3}$ Department of Business Administration, Faculty of Management, Universiti Teknologi Malaysia, Skudai, Johor \\ Bahru, Malaysia \\ ${ }^{4}$ Department of Accounting \& Finance, Faculty of Management, Universiti Teknologi Malaysia, Skudai, Johor \\ Bahru, Malaysia \\ Correspondence: Raghed Ibrahim Esmaeel, Department of Business Administration, Faculty of Management, \\ Universiti Teknologi Malaysia, Malaysia. E-mail: ragheedibrahimee@gmail.com
}

Received: March 16, 2015 Accepted: November 3, 2015 Online Published: November 23, 2015

doi:10.5539/ass.v11n28p37 URL: http://dx.doi.org/10.5539/ass.v11n28p37

\begin{abstract}
Supply-chain management (SCM) is considered one of the essential parts of international marketplaces. SCM comprises a number of paradigms such as Lean, Agile, Resilient, and Green (LARG). This research explains that an advanced manufacturing technology has a significant effect on the relationship between LARG-supply chain (SC), and SC performance. The correlation variables LARG-SC and supply SC performance is identified. A suitable theory is also investigated. This study utilizes several library entrances toward assembly knowledge. The framework of research is to determine each variable, which comprises independent variables, moderators, and dependent variables.
\end{abstract}

Keywords: lean supply chain, agile supply chain, resilient supply chain, green supply chain, advanced manufacturing technology (AMT), supply chain performance, LARG-SC

\section{Supply Chain Management}

Tan (2001) demonstrated that SCM is an effective supply scheme used by industrialists. This scheme can be used to explain several activities such as transportation, logistic tasks, and retailing. SCM also determines such value-added activities as those related to raw materials, end users, and recycling

Melnyk et al. (2009) indicated that SCM is a support field of study transformation. SCM has a competitive advantage in firms and organizations. The utilization of SCM is enhanced because of the increased information system, administration, science, logistics, and operation management. SCM employs optimism methods and used resources.

\section{2. (Lean, Agile, Resilient, and Green)-LARG-Supply Chain}

Cabral et al. (2011a) considered that LARG-SC models and introduced similar characteristic management philosophies. LARG-SC plays an important role in the worldwide marketplace.

Carvalho and Cruz-Machado (2009) applied LARG models to SC. LARG-SC models generally have the same international objective to meet consumer requirements. However, LARG models differ in their particular objectives. Lean SC is used for waste minimization; agile SC is aimed at a rapid reaction towards marketplace modifications, resilient SC pertains to capabilities that should be effectively met; and green SC aims to achieve low environmental impacts. 


\subsection{Lean SCM}

Liu et al. (2013) demonstrated that lean SCM is adequately new concept.

Mukunju (2014) indicated that Lean SCM, supports commercial banks and firms by developing financial and non-financial perspectives.

\subsection{Agile SCM}

Ren (2010) demonstrated that agile SCM considers similar modern patterns of the management system and comprises information streams and financial flows.

Liu et al. (2006) regarded agile SCM as a system structure during the introduction of a practical idea.

Jeffery (2005) clarified that agility refers to the capability to fit consumer needs and recognize the modifications in a marketplace efficiently.

\subsection{Resilient SCM}

Resilience is considered important in SCM in addition to supporting administrative theory (Pettit, 2008).

Falasca et al. (2008) mentioned that resilience determined a capability used in the SC system.

Spiegler et al. (2012) illustrated the adaptability of SC during the arrangement of unpredictable events, responding to disruptions, and sustaining progress operations.

\subsection{Green $S C M$}

Hsu and Hu (2008) demonstrated that green SCM is a proactive approach developed during the improvement of the environmental performance of operations following end products within a suitable requirement of an environmental regulation.

Zhu et al. (2010) indicated that green SCM is an environmental innovation.

Paul et al. (2014) determined that green SCM not only improves the capability of SCM but also achieves a low ecological effect. Green SCM also comprises several goals, such as quality, low cost, reliability, good performance, energy usage effectiveness, and high development activity.

\section{Advanced Manufacturing Technology (AMT)}

Singh and Shishodia (2012) divided AMT into: pure technological instruments (hardware) and management tools (manufacturing practice software).

Xie and Xie (2014) demonstrated that AMT is a vital combination of established manufacturing and high technologies. AMT determines the significant effect between national economic development and governmental support capability enhancement.

Based on the previous studies, the researcher regarded AMT a vital element in the developmental operation of all company activities. Thus, AMT will be supported to increase production, thereby achieving a high quality and an excellent performance.

\section{Supply Chain Performance}

Pasutham (2012) determined that SC performance is measured by identifying upstream integrated suppliers (supplier relationship management) downstream customers (customer relationship management), enterprises (internal SCM), and decision-making levels (strategic and operational).

Zhang and Okoroafo (2015) implied that SC performance is determined by its capability supply chain to deliver appropriate production in the exact place at the exact time.

Stone (2012) regarded SC performance as a drive that leads to the determination of internal and external performances.

\section{Research Methodology with the Hypotheses Investigated}

This study determines a number of hypotheses during its introduction of the conceptual framework. The role of AMT as a mediating variable between LARG-SC and SC performance is demonstrated. This study includes two main variables. The first one is an independent variable (i.e., LARG-SC), and the second one is a dependent variable (i.e., SC performance). Seven variable quantities are also included, such as LARG-SC, lean SC, agile SC, resilient SC, green SC, SC performance and AMT. Table 1 shows the variables. We explain a number of hypotheses, and use them in the conclusion. The hypotheses are as follows: 
Table 1. Theoretical background of hypotheses

\begin{tabular}{lll}
\hline Hypotheses & Variables & Theoretical Background \\
\hline H1 & LARG-SC, SC performance & Azevedo et al. (2012); Azevedo et al. \\
H1-A & Lean SC, SC performance & (2011) \\
H1-B & Agile SC, SC performance & Arif-Uz-Zaman (2012); Daud (2010) \\
H1-C & Resilient SC, SC performance & Betts and Tadisina (2009) \\
H1-D & Green SC, SC performance & Pettit (2008); Soliman et al. (2013) \\
H2 & LARG-SC, AMT & Mervani et al. (2005); Yu et al. (2014); \\
H2-A & Lean SC, AMT, SC Performance & Maleki et al. (2011) \\
H2-B & Agile SC, AMT, SC Performance & Aryee et al. (2005) \\
H2-C & Resilient SC, AMT, SC Performance & DeGroote and Marx (2013) \\
H2-D & Green SC, AMT, SC Performance & Yu and Liu (2013) \\
H3 & AMT, SC Performance & Li (2011) \\
H4 & LARG-SC, AMT, SC performance & Li et al. (2013) \\
\hline
\end{tabular}

- H1: LARG-SC has a positive effect on SC performance.

- H1-A: A positive relationship exists between Lean SC and SC performance.

- H1-B: A positive relationship exists between agile SC and SC performance.

- H1-C: A positive relationship exists between resilient SC and SC performance.

- H1-D: A positive relationship exists between green SC and SC performance.

- H2: AMT moderates the relationship between LARG-SC and SC Performance.

- H2-A: AMT moderates the relationship between lean SC and SC Performance.

- H2-B: AMT moderates the relationship between agile SC and SC Performance.

- H2-C: AMT moderates the relationship between resilient SC and SC Performance.

- H2-D: AMT moderates the relationship between green SC and SC Performance.

- H3: AMT has a positive influence on SC performance.

- H4 : AMT moderates the relationship between LARG-SC and SC Performance.

\section{- H1: LARG-SC has a positive effect on SC performance.}

Azevedo, et al. (2012) examined the connect between SCM practices and LARG-SC. The relationship among LARG-practices, SC performance, and SC performance measures, which are accompanied by considerable practices because of the achievement of inventory levels, is also identified. The significantly affected element in an operational performance is considered as a vital element in a development firm. The same paradigm exists in a distribution SC.

Azevedo, et al. (2011) indicated set of SCM practices comprising LARG-methods. LARG-practices affect SC performance with its measures.

- H1-A: LARG-SC has a positive effect on SC performance

Arif-Uz-Zaman (2012) explained an important efficiency method behind empowering the measuring performance of lean SCs, which comprises quantitative and qualitative indicators.

Daud (2010) determined the relationship between lean SC and SC performance, which obtains benefits from the society and firm during the introduction of knowledge and experience and from the competitive marketplace.

\section{- H1-B: A positive relationship between Agile SC and SC performance}

Betts and Tadisina (2009) tested and investigated the relationship among the roles moderating of SC collaboration, SC performance and agile SC. A high degree of SC collaboration indicates a significant effect on improving SC performance because of its achievement of agile SC.

- H1-C: A positive relationship between Resilient SC and SC performance

Pettit (2008) revealed that a highly resilient SC indicates considerable capability to contribute in improving SC 
performance.

Soliman, et al. (2013) indicated that the structure of resilient SC should contain the implementation of several activities not only emphasizing the effectiveness of SC but also comprising strategic decisions. An effective SC performance will achieve the optimum firm performance and thereby the optimum SC network.

\section{- H1-D: A positive exists relationship between geen SC and SC performance.}

Hervani, et al. (2005) showed that the essential goals of green SCM/performance management (GSCM/PM) comprise external reporting (an economic payment) and internal control (best enterprise performance) in addition to internal analysis (determining the business better and continuous improvement). GSCM/PMS may comprise determining increases in waste elimination, recovery, recycling, and cost containment, as well as eliminating of additional dealing with time (comprising energy with raw materials).

Yu, et al. (2014) identified the relationship between green SCM and the dimensions of operational performance, and determined the measurements of SC performance.

Mutingi, et al. (2014) regard green SC as vital in improving the performance management system. Green SC is also a new comprehensive index that may be used to combine performance appraisal and analysis of environmental and economic performances.

\section{- H2: LARG-SC has a positive influence on the AMT.}

Maleki, et al. (2011) regarded that LARG-SC as an integrated philosophy. LARG-SC comprises several features, such as organization system, human knowledge system, performance measure, and information system.

SC is built on technology and integration and comprises several aspects, such as information technology, management control, decision analysis, and strategic planning.

Espadinha-Cruz et al. (2011) demonstrated that LARG-SCM supports decision-making operations, and the optimal improvement of LARG-SC, during its integration by interoperability requirement, which considers information technology. Interoperability comprises a determinate benchmark of all firms' activities.

\section{- H2-A: AMT moderates the relationship between Lean SC and SC Performance}

Aryee, et al. (2005) illustrated that the integrated SC is considered one of the fundamentals of lean SC. Their study also implied the relationship among AMT, integrated SC, and organizational performance. Their study explained that technology supports a company by providing raw materials until obtaining customer-ready goods.

\section{- H2-B: AMT moderates the relationship between agile SC and SC Performance.}

DeGroote and Marx (2013) implied the relationship between information technology and agile supply SC, and analyzed the relationship between agile SC and firm performance. Their study also demonstrated that agile SC promotes the development of SC performance, which comprises a number of goals, such as sales, market share, profitability, speed to market, and consumer satisfaction. Therefore, information technology achieves the agility, which is considered an elemental adequacy by establishing a competitive advantage.

\section{- H2-C: AMT moderates the relationship between resilient SC and SC Performance.}

Yu and Liu (2013) remarked that information technology is vital in SCM. Information technology is required in (AMT). Thus, the relationship between green SC and information technology is determined through its goals, such as an energy ecology, environmental protection, and green production.

\section{- H2-D: AMT moderates the relationship between green SC and SC Performance}

Li (2011) illustrated that the green SCM is related to AMT, which include just -in- time manufacturing. Environmental performance is considered a vital element of SC performance.

\section{- H3: AMT have a positive influence on SC performance.}

Li, et al. (2013) implied that the relationship between SC performance and AMT through its implementation of entropy theory by calculating methods per section indicator entropy. Thus, SC performance is related to AMT, which includes stages of AMT, namely,before using AMT, after AMT investment, the middle of AMT investment, and the period of AMT investment.

\section{- H4: AMT moderates the relationship between LARG- SC and SC Performance}

Cabral, et al. (2011b) demonstrated the relationship among LARG-SC, AMT, and SC Performance and established an information paradigm, which supports modern combined paradigms of SCM, such as LARG. Such an information model will supply all the essential information, which are considered basic in decision 
making to obtain the right decisions at the right time. The more optimistic SC performance is, the more integrated LARG is, which is regarded a vital element of LARG-SC. Their study also determined the influence of these practices on several aspects, such as cost, service level, lead time, and product quality. These paradigms not only comprise various levels but also classifies separate paradigms.

\section{Proposed Research Framework}

Table 1 shows that the conceptual framework of this study with LARG- SC has an essential role in achieving SC performance and consists of a mediator variable, called AMT. Therefore, a correlation exists among LARG-SC, AMT, and SC performance.The research framework is illustrated in Figure 1.

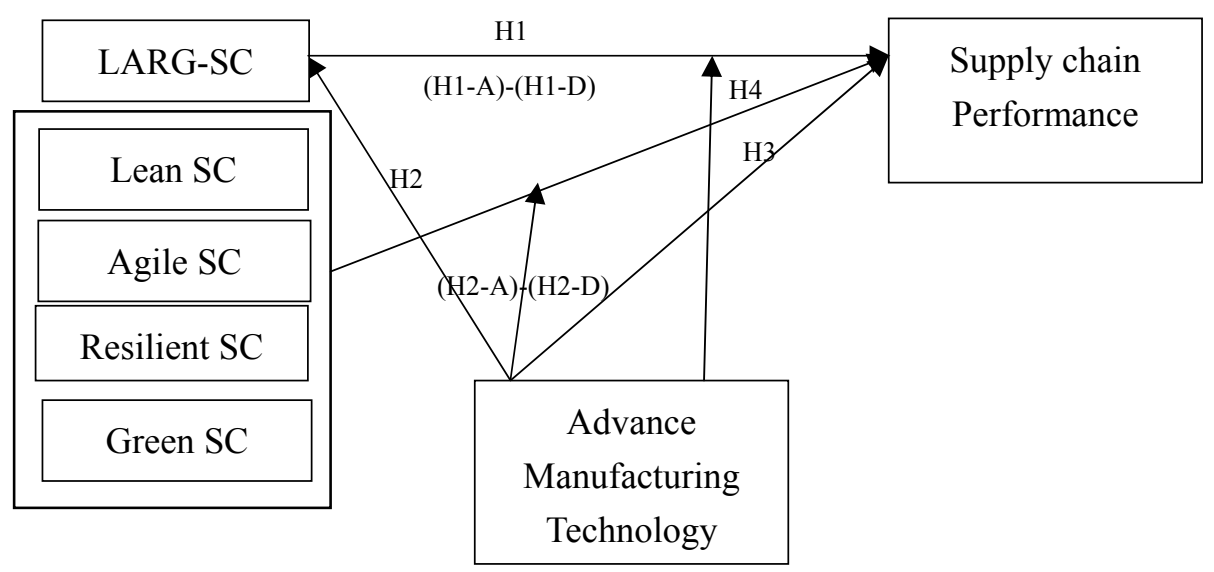

Figure 1. Proposed research framework

\section{Research Variables}

Table 2 presents several hypotheses and consists of independent variable, moderating variable, and dependent variable.

Table 2. Research variables

\begin{tabular}{llll}
\hline Hypothesis & $\begin{array}{l}\text { Independent } \\
\text { Variable }\end{array}$ & Moderating Variable & Dependant Variable \\
\hline H1 & LARG-SC & & SC Performance \\
H1-A & Lean SC & & SC Performance \\
H1-B & Agile SC & & SC Performance \\
H1-C & Resilient SC & & SC Performance \\
H1-D & Green SC & AMT & SC Performance \\
H2 & LARG-SC & AMT & \\
H2-A & Lean SC & AMT & SC Performance \\
H2-B & Agile SC & AMT & SC Performance \\
H2-C & Resilient SC & AMT & SC Performance \\
H2-D & Green SC & AMT & SC Performance \\
H3 & & AMT & SC Performance \\
H4 & LARG-SC & & SC Performance \\
\hline
\end{tabular}

\section{Conclusion and Recommendation for Future Research}

Based on previous studies, LARG-SC contributed to optimization of the firm paradigm in all activities through its empowerment enterprise to achieve model excellence in SC performance. Therefore, AMT may be used to increase quality, productivity, and market share. This study explains the relationship LARG-SC and SC 
performance. The relationship among each element of LARG-SC, SC performance, and AMT is also demonstrated. A theoretical model is used to assess the strength of the relationship between measures per variable quantities by introducing a conceptual model.

\section{Acknowledgements}

The authors would like to thank the Ministry of Higher Education (MOHE) in Iraq for providing a Scholarship granted by Universiti Teknologi Malaysia (UTM). We would like to take this opportunity to thank them.

\section{References}

Arif-Uz-Zaman, K. (2012). A fuzzy TOPSIS based multi criteria performance measurement model for lean supply chain. Queensland University of Technology (QUT), Australia.

Aryee, G., Lalwani, C., \& Naim, M. M. (2005). Supply chain integration using a maturity scale: Review of existing frameworks. Proceedings of the 2005 Proceedings of 16th Annual Conference of POMS, Chicago, IL, 1-20.

Azevedo, S. G., Carvalho, H., \& Cruz-Machado, V. (2011). A proposal of LARG supplies chain management practices and a performance measurement system. International Journal of e-Education, e-Business, e-Management and e-Learning, 1(1), 7-14. http://dx.doi.org/10.7763/IJEEEE.2011.V1.2

Azevedo, S., Carvalho, H., \& Cruz-Machado, V. (2012). Proposal of a conceptual model to analyses the influence of LARG practices on manufacturing supply chain performance. Journal of Modern Accounting \& Auditing, 8(2), 174-184.

Betts, T., \& Tadisina, S. K. (2009). Supply chain agility, collaboration, and performance: How do they relate? Proceedings of the 2009 POMS 20th Annual Conference U.S.A.

Cabral, I., Espadinha-Cruz, P., Grilo, A., Puga-Leal, R., \& Cruz-Machado, V. (2011). Decision-Making Models for Interoperable Lean, Agile, Resilient and Green Supply Chains. Proceedings of the 2011a Proceedings of the International Symposium on the Analytic Hierarchy Process.

Cabral, I., Puga-Leal, R., Grilo, A., \& Cruz-Machado, V. (2011). An information model in lean, agile, resilient and green supply chains. Proceedings of the $2011 \mathrm{~b}$ Communication Software and Networks (ICCSN), 2011 IEEE 3rd International Conference on. 27-29 May 2011, 776-780. http://dx.doi.org/10.1109/iccsn.2011. 6015004

Carvalho, H., \& Cruz-Machado, V. (2009). Integrating lean, agile, resilience and green paradigms in supply chain management (LARG_SCM). Supply Chain Management, 27-48.

Daud, A. (2010). A Study On Lean Supply Chain Implementation In Malaysia's Electrical And Electronics Industry: Practices And Performances. Master in Business Administration, USM, Malaysia.

DeGroote, S. E., \& Marx, T. G. (2013). The impact of IT on supply chain agility and firm performance: An empirical investigation. International Journal of Information Management, 33(6), 909-916. http://dx.doi. org/10.1016/j.ijinfomgt.2013.09.001

Espadinha-Cruz, P., Grilo, A., Puga-Leal, R., \& Cruz-Machado, V. (2011). A model for evaluating Lean, Agile, Resilient and Green practices interoperability in supply chains. Proceedings of the 2011 Industrial Engineering and Engineering Management (IEEM), 2011 IEEE International Conference on. 6-9 Dec. 2011. 1209-1213. http://dx.doi.org/10.1109/IEEM.2011.6118107

Falasca, M., Zobel, C. W., \& Cook, D. (2008). A decision support framework to assess supply chain resilience. Proceedings of the 2008 Proceedings of the 5th International ISCRAM Conference, 596-605.

Hervani, A. A., Helms, M. M., \& Sarkis, J. (2005). Performance measurement for green supply chain management. Benchmarking: An International Journal, 12(4), 330-353. http://dx.doi.org/10.1108/1463 5770510609015

Hsu, C. W., \& Hu, A. H. (2008). Green supply chain management in the electronic industry. International Journal of Environmental Science \& Technology, 5(2), 205-216. http://dx.doi.org/10.1007/BF03326014

Jeffery, M. M. (2005). Achieving cost-effective supply chain agility for the semiconductor industry. 3193484 Ph.D., University of Central Florida, Ann Arbor. Retrieved from https://vpn.utm.my/docview/305358684? accountid $=41678$ ProQuestDissertations\&ThesesGlobaldatabase

Li, Q., Zi-Lian, Y., Hui, L., \& Peng, D. (2013). Measurement of the Advanced Manufacturing Technology Investment Impact on the Overall Supply Chain. Journal of Convergence Information Technology, 8(6). 
Li, Y. (2011). Research on the performance measurement of green supply chain management in China. Journal of Sustainable Development, 4(3), 101. http://dx.doi.org/10.5539/jsd.v4n3p101

Liu, S., Leat, M., Moizer, J., Megicks, P., \& Kasturiratne, D. (2013). A decision-focused knowledge management framework to support collaborative decision making for lean supply chain management. International Journal of Production Research, 51(7), 2123-2137. http://dx.doi.org/10.1080/00207543.2012.709646

Liu, Z., Liu, Y., \& Chai, Y. (2006). Agile Supply Chain Management System in periodical balancing environment Proceedings of the 2006. In International Conference on Networking, Sensing and Control (pp. 238-243).

Maleki, M., da Cruz, P. E., Valente, R. P., \& Machado, V. C. (2011). Supply Chain Integration Methodology: LARGe Supply Chain. Encontro Nacional de Engenharia e Gestão Industrial 2011, 57.

Melnyk, S. A., Lummus, R. R., Vokurka, R. J., Burns, L. J., \& Sandor, J. (2009). Mapping the future of supply chain management: A Delphi study. International Journal of Production Research, 47(16), 4629-4653. http://dx.doi.org/10.1080/00207540802014700

Mukunju, E. W. (2014). Impact of lean supply chain management strategies on the performance of commercial banks in Kenya. University of Nairobi.

Mutingi, M., Mapfaira, H., \& Monageng, R. (2014). Developing performance management systems for the green supply chain. Journal of Remanufacturing, 4(1), 1-20. http://dx.doi.org/10.1186/s13243-014-0006-z

Pasutham, A. (2012). Supply chain performance measurement framework: Case studies on the Thai manufacturers. Doctor of Philosophy, Aston University.

Paul, V., Jayant, A., \& Vyas, C. (2014). Green Supply Chain Management: A Review. International Journal of Applied Engineering Research, 9(5), 607-613.

Pettit, T. J. (2008). Supply chain resilience: Development of a conceptual framework, an assessment tool and an implementation process. Degree Doctor of Philosophy, the Ohio State University, United States.

Ren, L. (2010). The Evaluation of Agile Supply Chain Management Based on AHP. Proceedings of the 2010 Knowledge Discovery and Data Mining, 2010. WKDD'10. Third International Conference on, 272-275. http://dx.doi.org/10.1109/WKDD.2010.62

Singh, M., \& Shishodia, Y. (2012). Advanced manufacturing Technologies: Literature Review. International Journal of Engineering, Business and Enterprise Applications (IJEBEA), 2(1), 22-25.

Soliman, K. M., Liu, S., \& Song, D. (2013). A proactive measurement framework for supply chain resilience (2PM-SCR): A conceptual framework Proceedings of the 2013 the international maritime transport \& logistics conference (MARLOG 2). Sustainable development of suez canal region: 17-19 MARCH 2013 United kingdom.

Spiegler, V. L., Naim, M. M., \& Wikner, J. (2012). A control engineering approach to the assessment of supply chain resilience. International Journal of Production Research, 50(21), 6162-6187. http://dx.doi.org/10.10 $80 / 0$ 0207543.2012.710764

Stone, J. (2012). The impact of supply chain performance measurement systems on dynamic behaviour in supply chains. Aston University.

Tan, K. C. (2001). A framework of supply chain management literature. European Journal of Purchasing \& Supply Management, 7(1), 39-48. http://dx.doi.org/10.1016/S0969-7012(00)00020-4

Xie, G. R., \& Xie, W. A. (2014). Advanced Manufacturing Technology-Virtual Manufacturing. Applied Mechanics and Materials, 543, 4638-4641. http://dx.doi.org/10.4028/www.scientific.net/AMM.543-547. 4638

Yu, Q., \& Liu, L. L. (2013). The Application of Information Technology in Green Supply Chain. Proceedings of the 2013 Advanced Materials Research, 3027-3030. http://dx.doi.org/10.4028/www.scientific.net/amr. 712-715.3027

Yu, W., Chavez, R., Feng, M., \& Wiengarten, F. (2014). Integrated green supply chain management and operational performance. Supply Chain Management: An International Journal, 19(5/6), 683-696. http://dx.doi.org/10.1108/SCM-07-2013-0225

Zhang, H., \& Okoroafo, S. C. (2015). Third-Party Logistics (3PL) and Supply Chain Performance in the Chinese Market: A Conceptual Framework. Engineering Management Research, 4(1), 38. http://dx.doi.org/10.5539/ emr.v4n1p38 
Zhu, Q., Geng, Y., Fujita, T., \& Hashimoto, S. (2010). Green supply chain management in leading manufacturers: Case studies in Japanese large companies. Management Research Review, 33(4), 380-392. http://dx.doi.org/ $10.1108 / 01409171011030471$

\section{Copyrights}

Copyright for this article is retained by the author(s), with first publication rights granted to the journal.

This is an open-access article distributed under the terms and conditions of the Creative Commons Attribution license (http://creativecommons.org/licenses/by/3.0/). 